\title{
Management of Facial Palsy Secondary to Temporal Bone Fracture
}

\author{
Najib Zouhair*, Anass Chaouki, Youssef Oukessou, Sami Rouadi, Redalah Elarabi Abada, Mohamed Roubal \\ and Mohamed Mahtar
}

Department of Otorhinolaryngology, Hospital of 20 august, Casablanca, Morocco

*Corresponding author: Najib Zouhair, Department of Otorhinolaryngology, Hospital of 20 august, Casablanca, Morocco

Received Date: February 07, 2020

Published Date: February 24, 2020

\begin{abstract}
Aim: The aim of this study was the analysis of clinical and paraclinical facial palsies occurring after fracture of the temporal bone so as therapeutic indications and outcomes.

Methods: We conducted a prospective and Evaluative study during three years in the department of ENT of the hospital of 20 august. Including all patients presented to the emergency unit with temporal bone Trauma with facial paralysis.

Results: 24 patients including $21 \%$ grade III, $21 \%$ grade IV, $14 \%$ grade V, 34\% grade VI, most often secondary to fracture of the right temporal bone with $56 \%$ and in $7 \%$ of cases it is bilateral. The electromyogram showed $7 \%$ of cases it is a moderate axonotmesis, $25 \%$ of cases moderate to severe axonotmesis, 34\% neurotmesis. The Schirmer test noted hyposecretion in 53\%. We performed 13 cases of surgical decompression of the three portions of the facial by the retro-auricular trans-mastoidal approach and one case of hypoglossal-facial anastomosis. The follow-up was monthly. The evolution was favorable in $80 \%$ with almost normal facial and auditory functions and an average decline of 2.7 years.

Conclusion: FP grade and it's time to installation are two crucial clinical elements in the treatment decision. Most authors agree to favor medical treatment for incomplete PF and secondary onset. Total and immediate FP, with a spontaneously adverse prognosis, classically call for surgical treatment.

Keywords: Facial palsy; Temporal bone fracture; Decompression
\end{abstract}

\section{Introduction}

FP secondary to temporal bone trauma is a complication related to a fracture through the intra-petrous facial canal that can sit in one or more of facial canal segments. It may result to a compression, stretching, inflammation or even nerve transection. It may cause a partial or total loss of facial muscles motor function which generally results in generalized hemifacial weakness and it causes major aesthetic and functional damage [1].

\section{Materials and Methods}

We conducted a prospective and Evaluative study during three years in the department of ENT of the hospital of 20 august. Including all patients presented to the emergency unit with temporal bone Trauma with facial paralysis (grades between III and VI of house and Brackmann grading system), Data collection was made through emergency registers, medical records, operative reports and follow-up in ENT consultation, variables studied was the clinical examination (Side, date of occurrence and circumstances of the PF, Degree of paralysis according to House-Brackmann's Classification), and the paraclinical assessment( Audiometry and Impedance Audiometry, acoustic reflex, Temporal bone CT scan, Schirmer's test, Electromyography (EMG), Electrogustometry were not performed) [2]. Medical treatment was based on prednisolone 1 to $1.5 \mathrm{mg} / \mathrm{kg} / 15$ days and progressive degression, active and passive physiotherapy without electrical stimulation, eye Care. Patients were reassessed monthly through one year and each year through 3 years. 


\section{Results}

We collected 24 patients with facial palsy among the 347 patients presented for temporal bone fracture during the 3 years of study, only 14 of them were operated. The mean age of patients was 23 years, with extremes between 8 and 35 years, all patients were men. Sixty-five percent of patients had polytrauma, $28 \%$ had an isolated temporal bone trauma. Thirty-four percent of patients had grade VI, $14 \%$ had grade V and the grade IV and III was in $21 \%$ each [3]. Facial palsy was noticed in the Right side in 56\% of cases, and bilateral in $7 \%$ of cases. otologic examination found hemotympanum in $42 \%$ of patients, post traumatic perforation in $36 \%$, cerebrospinal fluide otorrhea in $15 \%$. Temporal bone CT scan showed transverse extra labyrinthine fracture in $60 \%$ and mixed extra-labyrinthine fracture in $20 \%$ of all cases (Figure 1).
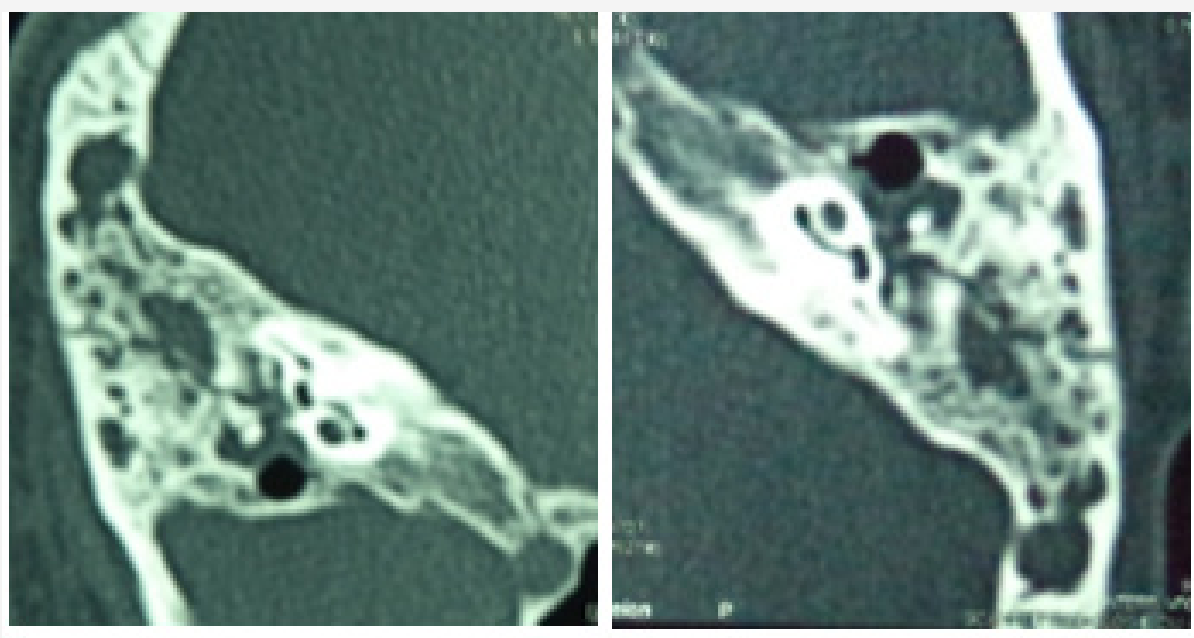

Figure 1: CT scan of a temporal bone fracture.

Electromyogramme found an axonotmesis in 66\% and neurotmesis in $34 \%$ of cases. Schirmer test showed an altered secretion in $53 \%$ of cases. The acoustic reflex was absent in $91 \%$ of cases. The geniculate ganglion was affected in $36 \%$ of cases, the tympanal segment in $20 \%$, the mastoidal segment in $14 \%$, the association of first and second segment was seen in $14 \%$ of cases. Ten patients received medical treatment associated with physiotherapy and eyes care [4]. Fourteen patients were operated, we proceeded to trans-mastoid approach: after mastoidectomy with posterior and superior tympanotomy. Facial decompression was performed in 13 cases (Figure 2). Just one patient with irreparable damages who wasn't decompressed so we proposed a hypoglosso-facial anastomosis (Figure 3). on the other hand, we found discontinuous ossicular chain in 52\% and we performed a disarticulation in $36 \%$ with ossiculoplasty type 2 by incus or cartilage transposition [5]. The evolution after 3 years of surgical and medical treatment found a remarkable improvement from grades 3 and 4 to grades 1 and 2 in $70 \%$ of cases and from grades 5 and 6 to grades 3 and 4 in 15\%.

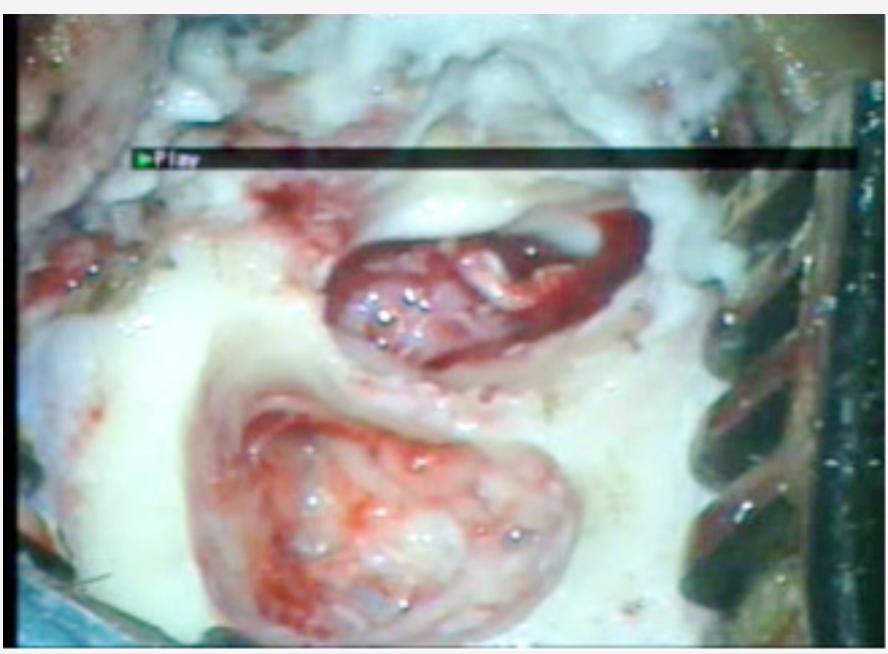

Figure 2: Transmastoidal approach for facial decompression. 


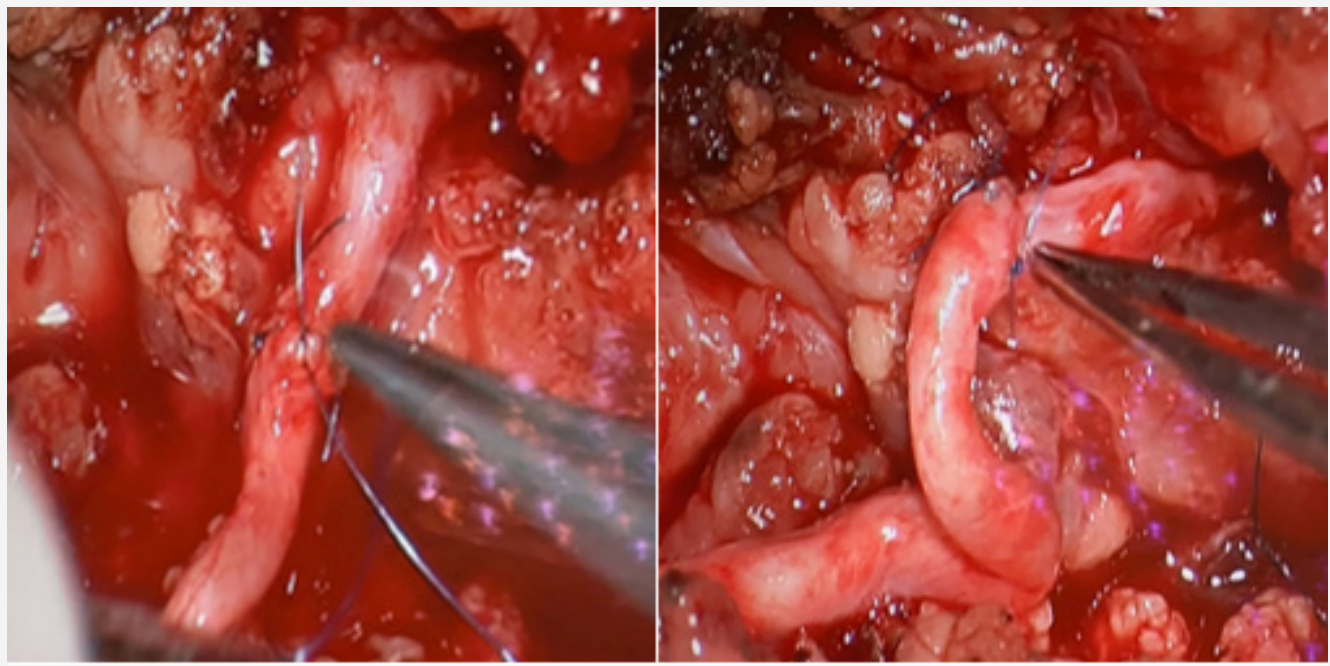

Figure3: Hypoglossofaciale anastomosis.

\section{Discussion}

The choice of the approach is controversed, although the transmastoidal combined or not to the sus petrous approach seems to be the most used by authors (Table 1). After decompression the majority of patients facial palysis turned to grades 1 or 2 except for Badenez \& al where the majority of facial palysis turned to grades 2 and 3 mostly [6-7] (Figure 4).

Table 1: Decompression approach according to authors.

\begin{tabular}{|c|c|c|c|c|}
\hline \multirow{2}{*}{ Series } & \multicolumn{3}{|c|}{ Surgical Approach } \\
\cline { 2 - 4 } & Trans-Mastoïdienne & Suspetrous & Combined & Trans-Labyrinthique \\
\hline Bodonez et al [2] 2006 & $8 \%$ & $15 \%$ & $58 \%$ & $19 \%$ \\
\hline Quaranta [3] 2001 & $100 \%$ & - & - & - \\
\hline Liu et al [4] 2014 & $15 \%$ & $80 \%$ & $5 \%$ & - \\
\hline Darrouzet et al [5] 2001 & $29 \%$ & - & $60 \%$ & $11 \%$ \\
\hline Notre Etude & $100 \%$ & - & - & - \\
\hline
\end{tabular}

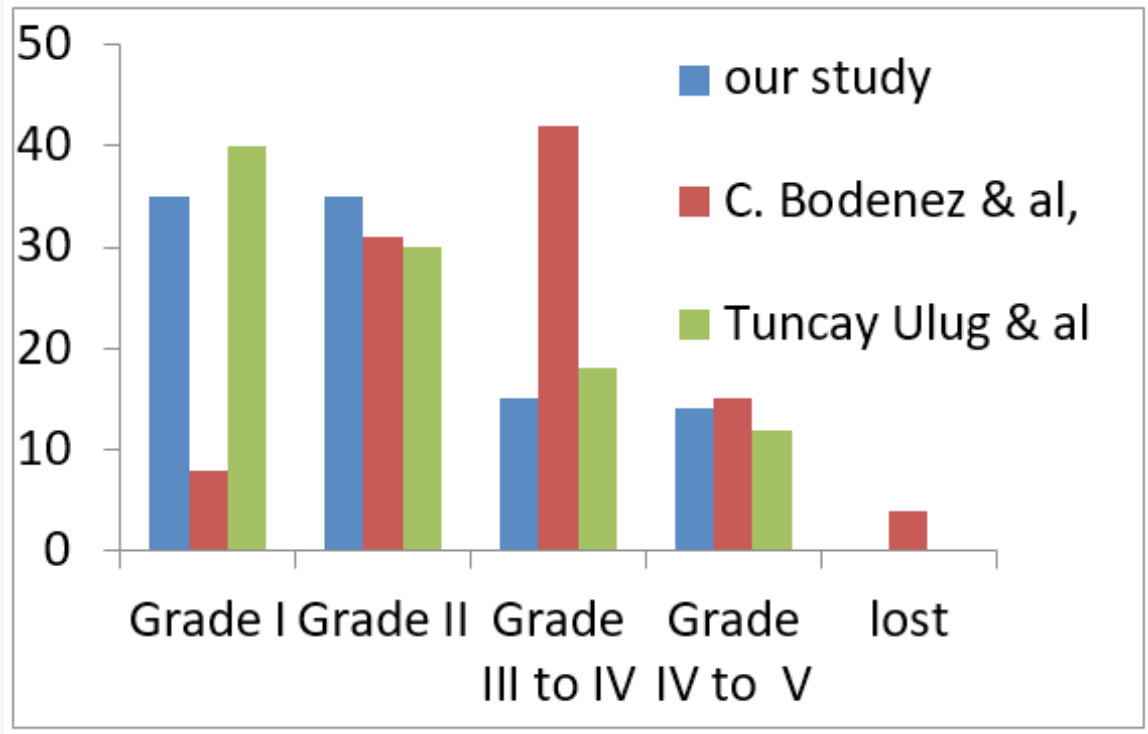

Figure 4: Evolution of FP grades after decompression according to studies. 


\section{Conclusion}

There is no therapeutic consensus. authors decide according to, clinical presentation and electromyography results time for surgical management is also controversial. It is recommended to operate in cases of: Immediate facial paralysis Grade VI, or Grade III and above resistant to oral corticosteroids.

Its satisfying to obtain a grade I to III after decompression, and a grade III to IV after nerve repair.

\section{Acknowledgement}

None.

\section{Conflict of Interest}

The authors declare no conflict of interests.

\section{References}

1. Labbé D, Bardot J, Bénateau H (2007) Peripheral facial paralysis surgery and sequelae EMC Tech Chir Chir. Plast Reconstr Esthét 2(4): 1-18.
2. Bodenez C, Darrouzet V, Rouanet Larriviere M, Barreau X, Liguoro D, et al. (2006) Facial paralysis after fracture of the temporal bone. Ann Otolaryngol Chir Cervico-Faciale 123(1): 9-16.

3. Quaranta A, Campobasso G, Piazza F, Quaranta N, Salonna I (2001) Facial nerve paralysis in temporal bone fractures: outcomes after late decompression surgery. Acta Otolaryngol (Stockh)121(5): 652-625.

4. Liu Y, Han J, Zhou X, Gao K, Luan D, et al. (2014) Surgical management of facial paralysis resulting from temporal bone fractures. Acta Otolaryngol (Stockh) 134(6): 656-660.

5. Darrouzet V (2001) Management of facial paralysis resulting from temporal bone fractures: Our experience in 115 cases. Otolaryngol Head Neck Surg 125(1): 77-84.

6. C Bodenez, V Darrouzet, M Rouanet Larriviere, X Barreau, D Liguoro, et al. (2006) Ann Otolaryngol Chir Cervicofac 123(1): 9-16

7. Ulug T, Arif Ulubil S (2005) Management of facial paralysis in temporal bone fractures a prospective study analyzing 11 operated fractures. Am J Otolaryngol 26: 230-238. 